Jurnal Jeumpa, 7 (2) Juli-Desember 2020

\title{
PERBANDINGAN MODEL PEMBELAJARAN TALKING STICK DAN BAMBOO DANCING TERHADAP PENINGKATAN HASIL BELAJAR SISWA DI KELAS VII SMP NEGERI 6 LANGSA TAHUN PELAJARAN 2018/2019
}

\author{
Devi Surianingsih ${ }^{1}$ Tri Mustika Sarjani ${ }^{2}$ Sofiyan $^{3}$ \\ Prodi Pendidikan Biologi Fakultas Keguruan Dan Ilmu Pendidikan \\ Universitas Samudra \\ Email : devisuryaningsih7@gmail.com
}

\begin{abstract}
ABSTRAK
Pendidikan adalah suatu proses dalam rangka mempengaruhi siswa agar dapat menyesuaikan diri sebaik mungkin terhadap lingkungannya. Berdasarkan hasil observasi yang penulis lakukan di SMP Negeri 6 Langsa, diperoleh beberapa informasi bahwa terdapat beberapa faktor yang menyebabkan rendahnya hasil belajar IPA. Beberapa permasalahan tersebut antara lain; kurangnya minat siswa dalam belajar IPA, kurangnya keaktifan siswa dalam belajar khususnya pembelajaran IPA, dan nilai hasil ujian IPA mata pelajaran biologi rata-rata 65 (enam puluh lima) rata-rata tersebut masih dibawah nilai KKM yaitu 75 . Solusi untuk meningkatkan kualitas pembelajaran dan membuat siswa aktif dalam belajar dengan menerapkan model talking stick dan model bamboo dancing dalam pembelajaran IPA. Tujuan penelitian untuk mengetahui adanya perbandingan model pembelajaran Talking Stick dan Bamboo Dancing terhadap peningkatan hasil belajar siswa kelas VII di SMP Negeri 6 Langsa Tahun Pelajaran 2018/2019 dan untuk mengetahui seberapa besar perbandingan model pembelajaran Talking Stick dan Bamboo Dancing terhadap peningkatan hasil belajar siswa kelas VII di SMP Negeri 6 Langsa Tahun Pelajaran 2018/2019. Metode penelitian berupa quasy eksperimental design dengan populasi seluruh siswa kelas VII di SMP Negeri 6 Langsa yang berjumlah 73 siswa. Sampel yang terpilih dalam penelitian ini sebanyak dua kelas yaitu siswa kelas VII-2 yang berjumlah 23 siswa dan kelas VII-3 yang berjumlah 23 siswa. Instrumen penelitian berupa soal tertulis dalam bentuk pilihan ganda yang berjumlah 20 butir soal. Data dianalisis dengan menggunakan rumus statistik uji-t. Tidak terdapat perbedaan antara model pembelajaran talking stick dengan bamboo dancing terhadap peningkatan hasil belajar siswa di kelas VII SMP Negeri 6 Langsa tahun pelajaran 2018/2019. Besarnya hasil perbedaan antara model talking stick dengan model bamboo dancing terhadap peningkatan hasil belajar siswa di kelas VII SMP Negeri 6 Langsa adalah sebesar 1,1565.
\end{abstract}

Kata kunci : Talking Stick, Hasil Belajar, Bamboo Dancing.

\section{ABSTRACT}

Education is a process in order to influence students to adapt as best as possible to their environment. Based on the results of observations made by the author at SMP Negeri 6 Langsa, there is some information that there are several factors that cause the low learning outcomes of science learning. Some of these problems include; The lack of student interest in learning Science, the lack of student activeness in learning, especially science learning, and the average score of the science exam results for biology subjects of 65 (sixty five) on average is still below the KKM 
score of 75. Solutions to improve the quality of learning and make students active in learning by applying the talking stick model and the bamboo dancing model in science learning. The research objective was to determine the existence of a comparison of the Talking Stick and Bamboo Dancing learning models on the increase in learning outcomes of grade VII students at SMP Negeri 6 Langsa in the 2018/2019 academic year and to find out how much the comparison of the Talking Stick and Bamboo Dancing learning models on the improvement of learning outcomes of Grade VII students at SMP Negeri 6 Langsa for the 2018/2019 academic year. The research method was a quasy experimental design with a population of all seventh grade students at SMP Negeri 6 Langsa, totaling 73 students. The sample chosen in this study consisted of two classes, namely 23 students of class VII-2 and 23 students of class VII-3. The research instrument was written questions in the form of multiple choice, totaling 20 items. Data were analyzed using the t-test statistical formula. There is no difference between the talking stick learning model and bamboo dancing on the improvement of student learning outcomes in class VII SMP Negeri 6 Langsa in the 2018/2019 academic year. The amount of difference between the talking stick model and the bamboo dancing model on the improvement of student learning outcomes in class VII SMP Negeri 6 Langsa is 1.156.

Keywords: Talking Stick, Learning Outcomes, Bamboo Dancing.

\section{PENDAHULUAN}

Penyebab dari rendahnya hasil belajar siswa antara lain karena karakteristik materi pelajaran yang bersifat abstrak. Pembelajaran terhadap materi yang bersifat abstrak akan lebih mudah jika ditunjang dengan penggunaan media ajar yang sesuai guna memudahkan siswa untuk memahami materi yang sedang dipelajari, namun selama ini guru masih kurang maksimal dan inovatif dalam menggunakan media ajar yang sesuai dengan karakteristik materi dan tersebut kurang efektif untuk di gunakan. Menurut (Sardiman, 2010:72) “ Upaya yang di lakukan untuk meningkatkan hasil belajar dan aktifitas siswa adalah dengan model pembelajaran”. Model pembelajaran merupakan salah satu komponen pengajaran, model pembelajaran menempati peranan yang tidak kalah pentingnya dari komponen lainnya dalam kegiatan belajar mengajar. Tidak ada satupun kegiatan belajar mengajar yang tidak menggunakan model sebagai alat motivasi ekstrinsik dalam kegiatan belajar mengajar. Sedangkan menurut (Nata, 2013:23) “ Model pembelajaran sebagai salah satu komponen pendidikan yang terpenting juga mengalami perubahan". Strategi pembelajaran yang dituntut saat ini adalah strategi pembelajaran yang berpusat pada aktifitas peserta didik (student centris) dalam suasana demokratis, adil, manusiawi, memberdayakan dan mengairahkan, 
Jurnal Jeumpa, 7 (2) Juli-Desember 2020

mengembirakan membangkitkan minat belajar, merangsang timbulnya inspirasi, imajinasi, kreasi, inovasi, etos kerja, dan semangat hidup.

Model pembelajaran kooperatif pada umumnya merupakan model pembelajaran yang dimiliki PAIKEM (Sagala, 2012:65) berpendapat bahwa model pembelajaran bamboo dancing merupakan model yang memberikan kesempatan kepada siswa untuk berbagi informasi pada saat yang bersamaaan dengan pasangan yang berbeda secara teratur. Pembelajaran aktif, inovatif, kreatif, efektif, dan menyenangkan. Aktif dimaksudkan bahwa dalam proses pembelajaran guru harus menciptakan suasana sedemikian rupa hingga tidak membosankan.

Penyebab rendahnya prestasi belajar biologi disebabkan pada proses pembelajaran dengan menggunakan model pembelajaran yang tidak sesuai dengan materi yang diajarkan, seperti menggunakan metode ceramah, dimana pembelajaran berlangsung satu arah, guru menerangkan sementara siswa menyalin menyebabkan metode pembelajaran tersebut kurang efektif untuk di gunakan sehingga Hasil belajarpun menjadi rendah. Hasil observasi penelitian yang peneliti lakukan di kelas VIII di SMP Negeri 6 Langsa nilai siswa tuntas $\mathrm{KKM} \leq 75$ hanya sebanyak 59,9\%.
Berdasarkan latar belakang di atas penulis merasa tertarik untuk meneliti dengan judul "Perbandingan Model Pembelajaran Talking Stick dan Bamboo Dancing Terhadap Peningkatan Hasil Belajar Siswa Kelas VII di SMP Negeri 6 Langsa Tahun Pelajaran 2018/2019”.

\section{METODE PENELITIAN \\ Waktu dan Tempat Penelitian}

Penelitian ini dilakukan di SMP Negeri 6 Kota Langsa, sedangkan waktu penelitian adalah pada bulan Agustus sampai bulan September 2019.

\section{Populasi dan Sampel}

Populasi dalam penelitian ini adalah seluruh siswa kelas VII yang berjumlah 73 orang siswa yang terdiri dari 3 (tiga) kelas paralel yaitu kelas VII-1, VII-2, dan VII-3. Jumlah populasi kelas VII di SMP Negeri 6 Tahun Pelajaran 2018/2019 dapat dilihat pada tabel 1.1.

Tabel 1.1 Jumlah Siswa Kelas VII di SMP Negeri 6 Langsa

\begin{tabular}{|l|c|c|}
\hline No & Kelas & Jumlah \\
\hline 1 & VII-1 & 27 \\
\hline 2 & VII-2 & 23 \\
\hline 3 & VII-3 & 23 \\
\hline Total & & $\mathbf{7 3}$ \\
\hline
\end{tabular}


Jurnal Jeumpa, 7 (2) Juli-Desember 2020

\section{Sampel}

Sampel adalah bagian dari jumlah dan karakteristik yang dimiliki oleh populasi tersebut (Sugiyono, 2010:117). Mengingat populasinya homogen maka pengambilan sampel menggunakan random sampling yaitu 23 orang siswa kelas VII-2 sebagai kelas eksperimen I dan 23 orang siswa kelas VII-3 sebagai kelas eksperimen II.

\section{Metode Penelitian}

Meetode yang digunakan dalam penelitian ini adalah metode eksperimen. Metode eksperimen diartikan sebagai metode penelitian yang digunakan untuk mencari pengaruh perlakuan tertentu terhadap yang lain dalam kondisi yang terkendali (Riduwan, 2010:50). Metode ini merupakan penelitian eksperimen dengan menggunakan dua kelas yang bertujuan untuk mendeskripsikan kompetensi belajar siswa secara kognitif.

\section{Teknik Pengumpulan Data}

Teknik pengumpulan data dilakukan dengan menggunakan tes. Tes digunakan untuk mengukur ada atau tidaknya serta besarnya kemampuan objek yang diteliti (Arikunto, 2013: 266). Penelitian ini menggunakan tes untuk memperoleh data hasil belajar siswa kelas VII-2 model talking stick dan kelas VII-3 model bamboo dancing yang diperoleh melalui pemberian pretest dan postest. Pretest diberikan sebelum pembelajaran baik di kelas VII-2 dan kelas VII-3.

Instrumen penelitian adalah alat atau fasilitas yang digunakan oleh peneliti untuk mengumpulkan data agar pekerjaan lebih mudah dan hasilnya lebih baik sehingga lebih mudah diolah. Instrumen penelitian yang digunakan adalah tes tertulis. Tes terdiri dari soal pretest dan posttest yang berjumlah 20 soal pilihan ganda, dan diberikan alternatif jawaban (a, b, c, d,). Setiap soal yang dijawab benar oleh siswa diberi skor 1 , sedangkan yang salah diberi skor 0 .

\section{HASIL DAN PEMBAHASAN}

Penelitian ini menggunakan instrumen soal pretes dan postes yang diberikan kepada siswa kelas VII-2 sebagai kelas eksperimen 1 dengan menggunakan model pembelajaran talking stick dan kelas VII-3 sebagai kelas eksperimen 2 dengan menggunakan model pembelajaran bamboo dancing. Setelah semua data terkumpul, maka selanjutnya dilakukan pengolahan data dengan rumus-rumus yang telah diuraikan pada bab sebelumnya. Data yang digunakan adalah nilai yang diperoleh dari hasil nilai pretes dan postes. Berdasarkan hasil pengolahan data diatas diperoleh nilai thitung adalah 1,1565, sedangkan nilai tabel untuk dk 
Jurnal Jeumpa, 7 (2) Juli-Desember 2020

44 pada taraf signifikan $\alpha=0,05 \%$ adalah 2,0168. Jadi, nilai $-\mathrm{t}$ tabel $\leq \mathrm{t}$ hitung $\leq+\mathrm{t}$ tabel $(-$ 2,0168 < 1,1565 < 2,0168), maka Ho diterima dan Ha ditolak, maka hipotesis nihil (Ho) diterima. Dengan demikian, dapat disimpulkan bahwa tidak terdapat perbedaan antara model pembelajaran talking stick dengan model bamboo dancing terhadap peningkatan hasil belajar siswa di kelas VII SMP Negeri 6 Langsa tahun pelajaran 2018/2019.

\section{Berdasarkan rata-rata nilai} peningkatan hasil belajar siswa dengan menggunakan model pembelajaran talking stick yaitu sebesar 73,70 dan rata-rata nilai hasil belajar siswa dengan menggunakan model pembelajaran bamboo dancing sebesar 66,09 dan kriteria peningkatan hasil belajar siswa dengan penerapan model pembelajaran talking stick yaitu sebesar 107\% tergolong sangat tinggi serta kriteria peningkatan hasil belajar siswa dengan penerapan model pembelajaran bamboo dancing yaitu sebesar 73\% tergolong tinggi.

Nilai peningkatan hasil belajar siswa dengan menggunakan model pembelajaran talking stick dapat meningkatkan hasil belajar siswa lebih tinggi dibandingkan dengan model pembelajaran bamboo dancing. Meningkatnya hasil belajar menunjukkan terjadinya peningkatan pemahaman terhadap materi yang dipelajari. Hal ini sesuai dengan pendapat (Rizki, 2018: 56) yang menyatakan bahwa "Siswa akan belajar dengan baik apabila mereka terlibat secara aktif dalam segala kegiatan di kelas dan berkesempatan untuk menemukan sendiri”. Hal yang dapat dirasakan oleh peneliti, dengan pengaplikasian model pembelajaran tersebut secara tidak langsung materi yang diperoleh siswa bukan diperoleh dari guru. Melainkan, para siswalah yang berpikir secara mandiri mengenai permasalahan yang diperoleh pada materi yang sedang dibahas.

Pengunaan model pembelajaran talking stick sangat baik karena secara aktif melibatkan seluruh siswa untuk menyampaikan idenya pada sesama siswa sehingga timbul ide-ide yang baru untuk dikembangkan sedang model pembelajaran bamboo dancing siswa hanya mengingat apa yang dia pelajari/hafal dibuku tersebut. Berdasarkan pengalaman saat penelitian siswa sangat aktif dan saling berbagi informasi pada model pembelajaran talking stick.

\section{KESIMPULAN}

Berdasarkan dari hasil penelitian yang telah dilakukan oleh penulis, maka dapat disimpulkan bahwa "tidak terdapat perbedaan antara model pembelajaran talking 
Jurnal Jeumpa, 7 (2) Juli-Desember 2020

stick dengan bamboo dancing terhadap peningkatan hasil belajar siswa di kelas VII SMP Negeri 6 Langsa tahun pelajaran 2018/2019 dan besarnya hasil perbedaan antara model talking stick dengan model bamboo dancing terhadap peningkatan hasil belajar siswa di kelas VII SMP Negeri 6 Langsa adalah sebesar 1,1565".

\section{DAFTAR PUSTAKA}

Arikunto, S. 2013. Prosedur Penelitian Suatu Pendekatan Praktek. Jakarta. Rineka Cipta

Nata. 2013. Perspektif Model Pembelajaran. Jakarta: Kencana Media

Riduwan. 2010. Belajar Mudah Penelitian untuk Guru, Karyawan dan Peneliti Pemula. Bandung: Alfabeta.
Rizki, Amalia Nur. 2018. "Perbandingan Motivasi Hasil Belajar Melalui Model Pembelajaran Kooperatif Tipe Two Stay Two Stray (TSTS) dengan Tipe Group Investigation (GI) Pada Siswa Kelas VII SMPN 8 Bulukumba", Jurnal Biotek. Vol 6 (1).

Sardiman. 2011. Motivasi dan Interaksi Belajar Mengajar. Jakarta: Rineka Cipta

Sagala. 2012. Konsep dan Makna Pembelajaran. Bandung: Alfabetha

Sudjana, Nana. 2009. Evaluasi Hasil belajar. Bandung: Tarsito.

Sugiyono, 2010. Metode Penelitian Kuantitatif Kualitatif dan R \& D, Bandung: Penerbit Alfabeta 